\title{
The effect of differing high-carbohydrate diets on dental caries in the albino rat
}

\author{
Bx R. M. GREEN AND R. L. HARTLES \\ Department of Dental Sciences, School of Dental Surgery, University of Liverpool
}

(Received 25 August 1965-Accepted 21 Fanuary 1966)

\begin{abstract}
1. Fifty-six albino rats were distributed between four dietary groups in fourteen randomized blocks of four animals. Each block consisted of siblings and each member of the block received a different dietary treatment. 2 . The diets permitted normal growth and the only variations were: group I contained $67 \%$ sucrose, group 2 an equivalent amount of uncooked maize starch and groups 3 and $467 \%$ of finely ground Thin Wine and Morning Coffee biscuits respectively. 3. After $3 \mathrm{I}$ days on the diet, the animals were killed and assessed for dental caries. The rats of group $\mathrm{I}$ had significantly more caries than the other groups. The rats of group 2 had significantly less caries than the other groups. The biscuit diets produced significantly less caries than the sucrose diet, but significantly more caries than the starch diet.
\end{abstract}

Many workers have shown that dental caries can be induced in certain strains of rats when they are maintained on diets containing about two-thirds of sucrose (Sognnaes, 1955). The incidence of caries is reduced to a low value when sucrose is replaced by raw wheat starch (Grenby, I963) or by raw potato starch (Hartles \& Lawton, 1957). Raw starches do not contribute largely to the diet of contemporary civilized man and it seemed of interest to compare the effects in the rat of a cariogenic sucrose diet and a relatively non-cariogenic starch diet with those of diets containing equivalent amounts of manufactured high-carbohydrate foods commonly eaten by man, such as biscuits.

In further experiments with rats we have now found that two diets each containing $67 \%$ of a different biscuit were significantly less cariogenic than the high-sucrose diet, but more cariogenic than the high-starch diet.

\section{EXPERIMENTAL}

\section{Animals and management}

The albino rats used were from our own colony which had been bred from a nucleus of caries-susceptible animals kindly donated by the Harvard School of Dental Medicine (Hartles, Lawton \& Slack, 1956).

Fifty-six weanling rats, four from each of fourteen litters, were assigned one from each litter to the four dietary treatment groups. The rats were housed two to a cage in seven batteries of four cages, each battery housing two litters with one representative of each litter in each cage. The four dietary treatments were reproduced within each battery, and the treatments were assigned to the cages within the battery by the use of a table of random permutations. This distribution produced fourteen randomized complete blocks of four animals, each block consisting of siblings, and each member of the block receiving a different dietary treatment. As a result of this 
distribution groups $\mathrm{I}$ and 3 contained eight males and six females, groups 2 and 4 seven males and seven females. The rats were weighed at the start, at weekly intervals and at the end of the experiment.

Cages. The rats were housed in stainless steel cages, the top, bottom and fronts of which were constructed of $\frac{1}{4}$ in wire mesh, the back and sides were of sheet metal. The feeding cups were also made of stainless steel. It is necessary to avoid the use of galvanized cages and feeding cups in studying dental caries, since the gnawing activity of the rat may produce 'occlusal fillings' of zinc in the fissures of the molar teeth.

Duration of experiment. The animals were maintained on their respective diets for $3 \mathrm{I}$ days and then killed by diethyl ether inhalation.

\section{Diets}

Four diets were prepared as follows.

Diet $\mathrm{RC}_{5}$ (group I)-cariogenic diet (g/kg): sucrose (icing sugar; Tate and Lyle Ltd) 670, casein (British Drug Houses Ltd) 240, salt mixture A (Hartles \& Leaver, I96I) 40, groundnut oil (J. Bibby and Sons Ltd) 50 . To each $\mathrm{kg}$ of diet was added: thiamine hydrochloride $15 \mathrm{mg}$; riboflavine $15 \mathrm{mg}$, pyridoxine $5 \mathrm{mg}$, calcium pantothenate $25 \mathrm{mg}$, nicotinamide $25 \mathrm{mg}, p$-aminobenzoic acid $500 \mathrm{mg}$, choline chloride ${ }_{1} 500 \mathrm{mg}$, retinol (acetate) $20 \mathrm{mg}, \alpha$-tocopheryl acetate $250 \mathrm{mg}$, menaphthone $20 \mathrm{mg}$, ergocalciferol $200 \mu \mathrm{g}$.

The water-soluble vitamins were added dispersed in $20 \mathrm{ml}$ water; the fat-soluble vitamins were added to the groundnut oil.

Diet $\mathrm{RC}_{7}$ (group 2) was compounded as diet $\mathrm{RC}_{5}$ except that the icing sugar was replaced by uncooked maize starch.

Diet $\mathrm{RC} 8$ (group 3) was as $\mathrm{RC}_{5}$ except that the icing sugar was replaced by powdered Thin Wine biscuits (Wm. Crawford and Sons Ltd).

Diet RC9 (group 4) was as RC8 except that the biscuit was powdered Morning Coffee (Wm. Crawford and Sons Ltd).

The biscuits were powdered so as to pass through a $30-$ mesh sieve. They had the following percentage composition according to the manufacturers; the solids are expressed on a dry-weight basis.

\begin{tabular}{lcc}
\multicolumn{1}{c}{ Constituent } & $\begin{array}{c}\text { Thin Wine } \\
\text { biscuit }\end{array}$ & $\begin{array}{c}\text { Morning } \\
\text { Coffee } \\
\text { biscuit }\end{array}$ \\
Moisture & $2 \cdot 8$ & $2 \cdot 1$ \\
Protein & $8 \cdot 1$ & $6 \cdot 8$ \\
Fat & $\mathbf{I} \cdot \mathbf{1}$ & $\mathbf{1} 4 \cdot 4$ \\
Reducing sugar & $5 \cdot 3$ & $\mathbf{I} \cdot 8$ \\
Sucrose & $4 \cdot 6$ & $\mathbf{2 0} \cdot 5$ \\
Ash & $\mathbf{1} \cdot 53$ & $\mathbf{I} \cdot 38$ \\
Starch & $63 \cdot 3$ & $\mathbf{5 5} \cdot 0$ \\
Total carbohydrate & $73 \cdot 2$ & $77 \cdot 3$
\end{tabular}

The biscuit diets therefore contained about $50 \%$ carbohydrate. The diets were mixed mechanically and given to the animals in unrestricted amounts. The rats also had continuous access to deionized water. There was no evidence to suggest variation in consumption of food and water by any of the animals. 


\section{Assessment of dental caries}

The method used was essentially that of König, Marthaler \& Mühlemann (1958). This procedure has not been described in the English language except briefly by Van Reen, König, Ostram \& McClure (1962), and details of the method are therefore given.

After the animals had been killed the lower jaws were removed and placed in small, numbered, capped jars containing histological formal saline (10\%, v/v, formalin; $0.9 \%, \mathrm{w} / \mathrm{v}, \mathrm{NaCl}$ ) for a period of not less than $48 \mathrm{~h}$. The formal saline was then decanted and the jaws were left in the uncapped jars to allow the excess formal saline to evaporate. The jaws were removed from the jars and stripped of adhering soft tissue. The mandible was separated into its component halves and the molar teeth of each half-mandible were sectioned mesiodistally with an internal-rim rotary cutting machine (Jansen, I950) so that a series of longitudinal sections (usually six per halfmandible) of the molar teeth was produced. The sections were cut so that they were still bound together by the uncut bone of the lower border of the mandible. At this stage the molar teeth remained in situ but were traversed by a series of slits along the length of the three molars and extending down from the crowns to the roots. On completion of the cutting, each pair of half-mandibles was irrigated with Schiff's reagent (Gurr), delivered from a plastic squeeze bottle, for $10-\mathrm{I} 5 \mathrm{sec}$ and then flushed with distilled water and dried on tissue paper. The sections were then detached from the mandible by chopping or cutting with a heavy scalpel and arranged in two columns on a glass microscope slide, the right-hand column comprising the left half-mandible and the right half-mandible being on the left. The most lingual section was at the top, the most buccal at the bottom of the slide. The sections were allowed to dry in air and then covered with a strip of Sellotape. This provided a permanent record of the caries experience in the lower jaw of each animal. The first and second molars were examined for carious lesions which were revealed as purple staining areas against a background of pale pink. A possible explanation of the staining reaction is that the Schiff's reagent reacts with the formalin which has penetrated into the tissue, and that in those areas where there is some disruption of the tissue by the carious process more formalin is absorbed and hence a more deeply coloured stain appears. We have observed, however, that carious lesions in teeth which had not been fixed in formal saline still reacted with Schiff's reagent, suggesting the possibility of the presence of aldehydic groups in the carious lesion.

Assessment technique. The microscope slide containing the sections was examined with a dissecting microscope, assessed by the method of König et al. (1958), and each decayed fissure categorized as follows:

(A) A lesion where staining is confined to the enamel.

(T) A lesion in which there is staining in dentine but where there is no break in the continuity of the tooth tissues.

(B) A lesion in which there is staining in the dentine and where in addition there is a break in the continuity, in the enamel or in the dentine or at the dentino-enamel junction. 
(C) A lesion which is heavily stained in the dentine with some loss of enamel and the appearance of distinct microscopic cavitation.

The staining of the enamel only, on which the diagnosis of a category A lesion depends, is not a completely reliable indication of caries for, as Dalderup (I959) has shown, staining in the enamel may indicate the persistence of immature incompletely calcified enamel rather than the effect of a decalcifying process. In the study now presented the use of category $\mathrm{A}$ has been discontinued.

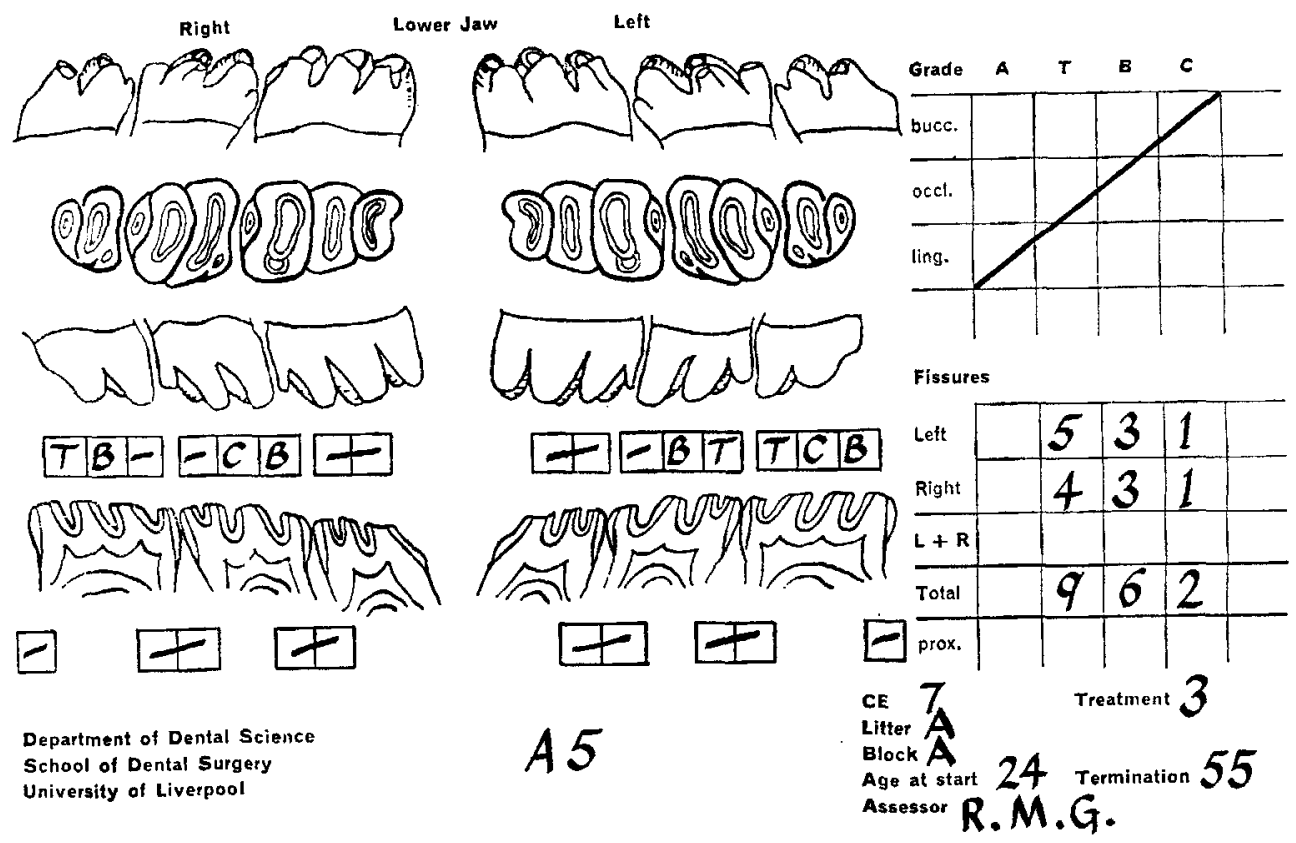

Fig. r. Record card used in the assessment of dental caries in the rat.

Only the first and second molars of the mandible were assessed for caries, the third molar erupts at a variable time during the experimental period and so is unsuitable for meaningful assessment. The caries experience of each animal therefore was based on the assessment of twelve fissures; each fissure usually appeared in more than one section and it was graded according to the most severe lesion observed in any section of that fissure.

The grading of the lesions was recorded on a specially designed card (Fig. I) similar to that used by König et al. (1958), and the sections were examined in such a way that the assessor was unaware of the dietary treatment that the animal had received. All the assessments were carried out by one examiner (R.M.G.) in order to minimize observer bias. On completion of the assessment, three scores were calculated for each animal: cumulative T-lesions, i.e. all lesions; cumulative B-lesions, i.e. all lesions except true T-lesions; and C-lesions. Cumulative counts are used on the basis that all large lesions must have started as small ones and then progressed. Examples of a normal fissure, $\mathrm{T}, \mathrm{B}$, and $\mathrm{C}$ lesions are shown in Pl. I. 


\section{RESULTS}

Dental caries. The results for the four groups are shown in Table I. Only the total number of lesions (cumulative $T$ ) were analysed statistically since the number of $\mathrm{B}$-lesions was insufficient for the purpose. There were no C-lesions in this experiment.

The total number of lesions present was subjected to an analysis of variance in which the total variation of the experiment was divided into that due to the treatments, that due to the blocks, and the residual or error variation. The analysis was conducted according to the pattern established by König et al. (1958), who concluded that under their conditions the 'cage' factor would be small and contribute little to the total variation, so that it was therefore omitted from the analysis. The total variation due to treatments was then further divided into two separate sets of orthogonal comparisons so that the significance of each comparison could be tested and given a valid level of significance (Table 2). Snedecor's $F$ test was used as the test of significance.

Table I. Caries experience and total weight gain of four groups of fourteen rats maintained on different high-carbohydrate diets for $3 \mathrm{I}$ days

\begin{tabular}{|c|c|c|c|c|c|}
\hline \multirow[b]{2}{*}{ Group } & \multirow[b]{2}{*}{ Diet } & \multicolumn{3}{|c|}{ No. of carious lesions per rat } & \multirow{2}{*}{$\begin{array}{c}\text { Weight } \\
\text { gain } \\
\text { (g) }\end{array}$} \\
\hline & & Cumulative $T^{*}$ & Cumulative $B^{*}$ & $\mathrm{C}$ & \\
\hline I & $\mathrm{RC}_{5}$, sucrose & $5 \cdot 78$ & $2.14 \pm 0.40 \dagger$ & 0 & 96 \\
\hline 2 & $\mathrm{RC}_{7}$, starch & 0.71 & 0 & $\circ$ & 95 \\
\hline 3 & RC 8, Thin Wine & 3.00 & $0.78 \pm 0.45 \dagger$ & o & IO4 \\
\hline 4 & $\begin{array}{l}\mathrm{RC} 9 \text {, Morning Coffee biscuit } \\
\text { Pooled standard error of group means }\end{array}$ & $\begin{array}{l}4.14 \\
\pm 0.30\end{array}$ & $0.85 \pm 0.27 \dagger$ & o & $\begin{array}{l}100 \\
+6 \cdot 9\end{array}$ \\
\hline
\end{tabular}

* The types of lesions are described on p. 3r9.

$\uparrow$ Standard error of individual group means.

Table 2. Troo sets of orthogonal comparisons of the number of carious lesions in groups of fourteen rats arising as a result of the dietary treatments, with the significance levels for each comparison

\section{Dietary treatment}

Sucrose versus all other treatments

Starch versus biscuits

Morning Coffee versus Thin Wine biscuits

Starch versus all other treatments

Sucrose versus biscuits

Morning Coffee versus Thin Wine biscuits
Level of significance

$P<0.001$

$P<0.001$

$P>0.05$

$P<0.001$

$P<0.01$

$P>0.05$

It can be seen that the maize-starch diet $\left(\mathrm{RC}_{7}\right)$ produced significantly less caries in the rat than the other three diets used. The sucrose $\operatorname{diet}\left(\mathrm{RC}_{5}\right)$ produced significantly more caries than the other diets. The difference between the caries experience of the rats maintained on the two biscuit diets did not reach a significant level.

Growth of animals. The animals remained healthy and alert throughout the experiment and grew normally. The extent of the variation in weight gains on the four diets is illustrated in Table $\mathrm{I}$. 


\section{DISCUSSION}

The provision of a nutritionally adequate diet containing $67 \%$ of sucrose in the form of icing sugar resulted, in the rat, in the production of a considerable degree of early dental caries. Of the twelve fissures at risk in the first and second mandibular molars, an average of almost half became carious after $3 \mathrm{I}$ days on the diet, and in more than one-sixth of the fissures caries had developed beyond the initial stage and had caused a break in tissue continuity (B-lesions). When the sucrose was replaced by uncooked maize starch the caries score was dramatically reduced so that an average of less than one fissure per animal was affected, and there were no advanced lesions. These two dietary regimes, therefore, provide a basis for assessing the relative cariogenicity of other carbohydrate foodstuffs in the rat.

It is widely believed that the indiscriminate consumption of manufactured confectionaries with a high carbohydrate content such as sweets, cakes, pastries and biscuits is a factor in the exacerbation of dental caries in man. There is, however, little direct experimental evidence to support this belief, nor is it likely to be forthcoming. One of the few studies to be reported is that of Gustafsson, Quensel, Lanke, Lundqvist, Grahnen, Bonow \& Krasse (1954), who showed that 'between-meal' eating of toffees resulted in an increased caries experience in a group of subjects living in an institution.

It is extremely dangerous to assert that the results obtained with one species may apply to another. It is, however, perhaps less inadmissible to consider that the relative cariogenicity of dietary regimes as determined on one species may have some general application. It seemed of interest therefore to test in the rat a manufactured product containing a high proportion of carbohydrate against defined diets, one of which was cariogenic and the other relatively non-cariogenic. With the co-operation of the manufacturers we chose two biscuits with similar total carbohydrate content. One of them, Thin Wine, contained $9.9 \%$ sugars, of which $4.6 \%$ was sucrose and $5.3 \%$ reducing sugar; the other, Morning Coffee, a slightly sweeter biscuit, contained $22 \cdot 3 \%$ sugars, of which $20.5 \%$ was sucrose and only $\mathrm{r} .8 \%$ reducing sugar. When incorporated into the rat diet both these biscuits produced dental caries at a level significantly less than that observed on the high-sucrose diet, but significantly greater than that produced on the high-starch diet. There was a suggestion that the Morning Coffee biscuit with its higher sugar content was more cariogenic than the Thin Wine biscuit but the differences were not statistically significant $(P>0.05)$ (Tables I and 2).

The observation that these biscuit diets were less cariogenic in the rat than the high-sucrose diet but more cariogenic than the starch diet raises certain intriguing possibilities. The biscuit diets appeared more cariogenic than might have been predicted from their comparatively low sugar content, and it may well be that the cooking process so modified either the composition or the consistency as to influence the cariogenicity of the biscuits. It is possible that cooking affected the physical characteristics so that the biscuit diet adhered more readily to the tooth surface. However, our observations did not indicate that this was an important factor in the situation.

There appear to be few studies which have been designed to determine the critical level of sucrose in a starch-sucrose mixture, or of any interaction between the two. 
British Fournal of Nutrition, Vol. 20, No. 2

Plate I
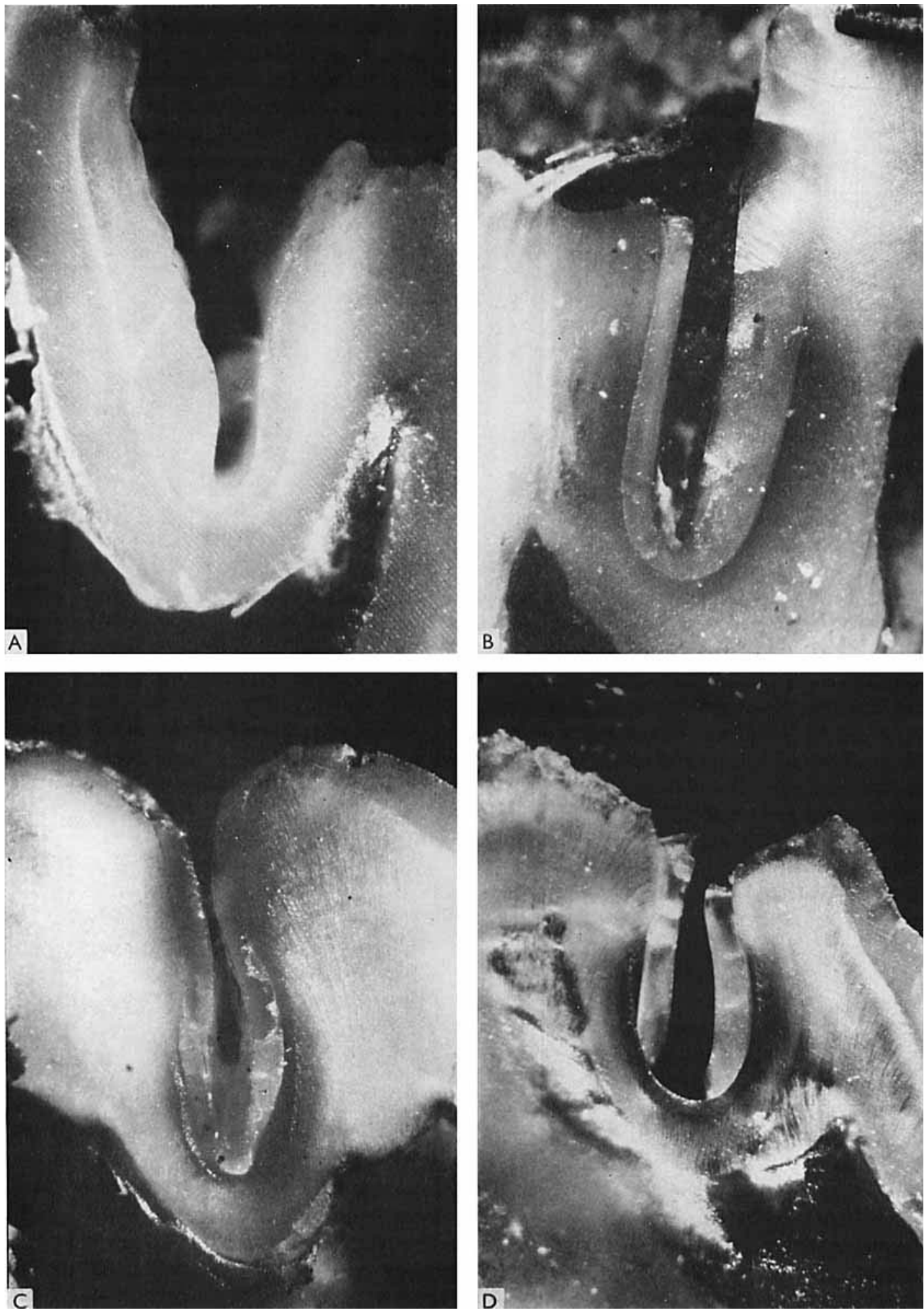

R. M. GREEN AND R. L. HARTLES

(Facing p. 323) 
Schweigert, Shaw, Phillips \& Elvehjem (I945) showed, in the cotton-rat, that replacement of half of the sucrose in the diet with fine dextrin did not reduce the severity of tooth decay, but that the replacement of three-quarters of the sucrose with dextrin caused some reduction in caries experience.

It is our intention therefore to determine the effect of caries experience in the rat of variation in the ratio of sucrose to starch in a high-carbohydrate diet, and to see if the cooking process has any effect on the cariogenicity of the dietary components. We are of the opinion that the comparative cariogenicity of manufactured products with a reasonably well defined composition may be assessed in the rat, particularly in relation to those products commonly eaten by man between the main meals.

We wish to thank Wm. Crawford and Sons Ltd, for their co-operation in providing the biscuits, Tate and Lyle Ltd, for the icing sugar and J. Bibby and Sons Ltd, for the groundnut oil. We are greatly indebted to Miss Beryl Morrison for her care and maintenance of the animals and for her skilled technical assistance. We are also grateful to the Medical Research Council for a grant to defray the expenses of this work.

\section{REFERENCES}

Dalderup, L. M. (1959). Nutrition and Caries. Amsterdam: Drukkerij Verdonk.

Grenby, T. H. (1963). Archs oral Biol. 8, 27.

Gustafsson, B. E., Quensel, C. E., Lanke, L. S., Lundqvist, C., Grahnen, H., Bonow, B. E. \& Krasse, B. (1954). Acta odont. scand. II, 232.

Hartles, R. L. \& Lawton, F. E. (1957). Br. F. Nutr. II, 13.

Hartles, R. L., Lawton, F. E. \& Slack, G. L. (1956). Br. $\mathscr{F}$. Nutr. ro, 234.

Hartles, R. L. \& Leaver, A. G. (I961). Archs oral Biol. 5, $3^{8 .}$

Jansen, M. T. (1950). F. dent. Res. 29, 401.

König, K. G., Marthaler, T. M. \& Mühlemann, H. R. (1958). Dt. Zahn- Mund- u. Kieferheilk. 29, 99. Schweigert, B. S., Shaw, J. H., Phillips, P. H. \& Elvehjem, C. A. (I945). F. Nutr. 29, 405.

Sognnaes, R. F. (editor) (r955). Advances in Experimental Caries Research. Washington, D.C.: American Association for the Advancement of Science.

Van Reen, R., König, K. G., Ostram, C. A. \& McClure, F. J. (1962). Archs oral Biol. 7, 48 I.

\section{EXPLANATION OF PLATE}

Examples of dental caries in the albino rat assessed according to the method of König et al. (1958).

(A) Normal fissure, no caries.

(B) T-lesion; note staining in both enamel and dentine (darker areas) but no loss of tissue continuity.

(C) B-lesion; staining in enamel and dentine together with loss of continuity at the dentino-enamel junction.

(D) C-lesion; staining with actual loss of tissue and beginning cavitation. 